\title{
OS PRÉ-JUÍZOS E A TRADIÇÃO NA ENFERMAGEM*
}

\author{
Alcinéa Eustáquia Costa** \\ Lélia Maria Madeira** \\ Marilia Alves**
}

COSTA, A.E. et al. Os pré-juizos e a tradição na enfermagem. Rev.Esc.Enf.USP, v.29, n.3, p. 261-6̧6, dez. 1995 .

As autoras buscaram identificar e refletir, à luz da concepção de GADAMER(1977) sobre os pré-juizos e a tradição, a revivificação dos mitos, estigmas e estereótipos da enfermagem, ao longo de sua trajetória histórica.

UNITERMOS: Historicidade da enfermagem. Tradição na enfermagem. Pré-juízos na enfermagem.

\section{INTRODUÇÃO}

A enfermagem como uma profissão da área da saúde, possui uma trajetoria histórica que tem sido estudada por diversos autores.

A evolução histórica do cuidado de enfermagem é descrito por ALMEIDA, ROCHA(1986), inicialmente, relacionada com o cuidado natural, intuitivo, que as familias dispensavam às crianças e doentes, visando mais o conforto da alma do enfermo.

Em um segundo momento, que compreende o inicio do Cristianismo até a Idade Média, predominou o modelo religioso da enfermagem, onde os agentes cram pessoas ligadas a igreja e que buscavam salvar suas almas salvando a alma do doente, atraves do cuidado. A prática da enfermagem, nesse perído, era independente da prática médica e sua ação não pressupunha ordens médicas ou planos terapêuticos.

\footnotetext{
* Trabalho apresentado à I)isciplina: "('ritica Marxiana às Ciéncias Sociais", do Curso de Pós-Craduação em Filosofia da PAFICH/UFMG.

** Doutorandas em Hnfermagem pela Escola de Enfermagem da LiSF/Convenio Escola Enfermagem IIPMC; Professoras da Fscola de Fnfermagem da UHMG.
} 
Com o início do capitalismo, para os mesmos autores, há também uma transição na enfermagem. A práticè, tanto da enfermagem, quanto da medicina se encontram no ambiente hospitalar, havendo uma subordinação da enfermagem à medicina $e$ a substituição do modelo religioso da enfermagem pelo cuidado e contrôle do ambiente do paciente. Inicia-se, assim, uma rígida disciplina na enfermagem, com a finalidade de normatizar e regulamentar a vida no hospital, prática esta bem desempenhada pela enfermagem, devido ao seu grande conhecimento da rotina hospitalar.

Em relação à mudança dos agentes da enfermagem, JAMIESON et al(1978), apontam ser este o início da laicização da profissão, que passa a ser exercida por mulheres de moral duvidosa (imorais, bêbadas, analfabetas) submetidas a extensas jornadas e péssimas condições de trabalho e cujo serviço passa a ser remunerado através de pagamento e comida exíguos.

No século XX, segundo ALMEild)A; ROCHA(1986), firma-se, sustentado por mulheres de classe média e alta, a ideologia da prática de enfermagem como vocação, um chamado ao auto-sacrif́cio. O modelo vocacional 6 comandado pela técnica disciplinar para tornar a enfermagem possível dentro da hierarquia de poder, com o objetivo de auxiliar o médico. A mudança da enfermagem tradicional para a moderna, focaliza mais o treinamento disciplinar que a construção do saber da enfermagem.

Ainda neste seculo, inicia-se o estudo e desenvolvimento das técnicas de enfermagem no cuidado com o doente, baseado na racionalização do trabalho, para dar conta da crescente hospitalização, redução de gastos e mais eficiência, assentados cada vez mais na divisão social e técnica do trabalho, dentro da propria enfermagem e entre a enfermagem e a medicina.

Como se verifica, a trajetória histórica da enfermagem trás consigo, diversos estigmas e preconceitos que são reforçados pelo fato de que, além de ser uma profissão de desempenho eminentemente manual, carrega ainda a fragilidade de, em todos os tempos, ter sido exercida por mulheres, sendo considerada portanto, como um trabalho socialmente desvalorizado.

Estas reflexões sobre a historia da profissão nos remetem ao presente, apontando a necesidade de se buscar a compreensão do momento atual. Encontramos nas ideias de GADAMER(1977) sobre os pré-juízos e a tradição, muita aderência à situação histórica e atual da enfermagem. Assim, baseadas nas idéias do referido autor, objetivamos, neste estudo, identificar a influência dos pré.juízos e da tradição na enfermagem.

\section{A ENFERMAGEM, SEUS PRÉ-JUÍZOS E SUA TRADIÇÃO}

Para (GADAMER(1977), a historicidade se concretiza na propria estrutura da compreensão histórica. Toda compreensão implica numa pré- 
comprcensão de um conjunto de tradições que projetamos nas possibilidades futuras. Essa pré-compreensão vai guiar a interpretação dos pré-juizos.

Pré-juízo, num primeiro momento, significa para o autor, opiniōes prévias do sujeito frente a coisa em si mesma; significa um juízo que se forma antes de uma validação definitiva de todos os momentos objetivamente determinantes; são as tradições revividas que nos conduzem à compreensão das coisas. Por isso, os pré-juízos de um indivíduo são muito mais que os scus juízos. Elles são a realidade histórica do seu ser; não significando um juízo falso, bem como o seu conccito não pode ser valorado positiva ou negativamente.

A "coisa"a ser interpretada não é estranha ao interprete, pois ambos fazem parte da historia. () interprete coloca à prova seus proprios pré-juízos, verificando se este permite um diálogo com a própria "coisa". Ambos pertencem à história à tradição do "ser no mundo".

GADAMER(1977) identifica a tradição com autoridade e afirma que os comportamentos humanos são condicionados pela história e, como seres históricos estamos comprometidos com o passado e imersos nas tradições. Estas possuem autoridade de transmissão que é aceita e incorporada por nós, determinando nossas instituições e comportamentos. O presente nada mais é do que o passado revivificado, ou seja, a história é a revivificação da tradição. Afírma ainda que a história não nos pertence, nós é que pertencemos à ela. O autor relaciona, também, a tradição à autoridade e diz que tudo que ć consagrado pela tradição possui autoridade e que autoridade é um atributo de pessoas que nada tem a ver com obediência cega à comandos, mas sim com "conhecimento".

Conforme mencionado anteriormente, autores que tratam da história da enfermagem, identificam estigmas, mitos, esteriótipos da enfermagem, relacionando-os ao período histórico correspondente. Em nossso estudo, buscaremos relacinálos aos pré-juízos conforme os concebe G $\Lambda$ DAMER(1977).

identifica:

HORTA(1975), discorrendo sobre os mitos da enfermagem,

- enfermeira - dama de caridade;

- enfermeira - ajudante do médico;

- enfermeira - executora de técnicas;

- enfermeira - aquela que cuida de doente;

- enfermeira - administradora.

Além desses mitos destacados por HORTA(1975), vale ressaltar a predominância do feminino na enfermagem c as consequências advindas desse 
fato. A posição da mulher na sociedade sempre influenciou a forma de desenvolvimento das profissões.

PINHEIRO(1959), em documento sobre a enfermagem brasileira já afirmava: "a mulher brasileira não conseguiu ainda emancipar-se da tutela masculina...até que ponto essa posição de inferioridade afeta a enfermagem?... Contando a enfermagem com um número restrito de homens, custa-lhe abrir caminhos numa sociedade inteiramente controlada por eles; falta-lhe agressividade e o prestígio necessários, talvez lhe falte também o espírito lógico que dirige o raciocínio, descobre argumentos e a estes dá força...Talvez porque a enfermagem exige o trabalho das mãos, não se lhe dá crédito de profissão que também utiliza o cérebro".

No momento atual, diversos autores se voltam à problemática do gênero nas profissões de predomínio feminino e, na enfermagem, MIRANIDA(1984) afirma: "Vejo a profissão como eminentemente feminina e que, como tal, incorpora quase todas as discriminações sofridas pelas mulheres no mercado de trabalho. $\Lambda$ profissão como outras é vítima de uma serie de desigualdades e preconceitos que precisam ser vencidos".

As colocações desses autores, nos reportam às idéias de GAIDAMER(1977), sobre os pré-juízos e a tradição. () predomínio do feminino tem influenciado a enfermagem desde os seus primordios, haja visto os mitos já mencionados que estão diretamente relacionados ao feminino, tais como: dama de caridade, ajudante de medico, executora de trabalhos manuais, dentre outros. (GERMANO(1983) afirma que tem sido amplamente difundido na enfermagem as qualidades inerentes ao bom profissional, que são: a obediência, o respeito à hierarquia, a humildade e o espirito de servir.

Os préjuízos, mantidos e introjetados através dos tempos, leva. nos a concordar com SILVA(1989), quando afirma que "o trabalho da enfermeira não é desprestigiado por ser feminino, mas é feminino por ser desprestigiado".

GADAMER(1977) diz que o que 6 consagrado pela tradição e pelo passado, possui uma autoridade velada porque nos determina silenciosamente. Em sua concepção somos apenas levados pela tradição: a história é finita, sendo os fatos apenas revivificados no transcurso da história. Na enfermagem, verificamos na literatura, diversos momentos em que se preconiza a necessidade de mudanças, sejam estas relativas à assistência, ao ensino ou a outros aspectos da profissão. No entanto, constata-se que, apesar de todos os esforços, essas mudanças permanecem limitadas, podendo isso ser atribuído a sua tradição e domínio do passado. A realidade dos costumes 6 e segue sendo algo válido por tradição e procedência.

O autor atribui a tradição uma autoridade de transmissão, relacionando-a com o conhecimento. Continua afirmando que a autoridade do superior 6 decorrente de sua visão mais ampla, do fato deste estar mais 
consagrado, isto é, saber mais. Desse modo, o reconhecimento da autoridade está sempre relacionado à idéia de que o que diz a autoridade não cé irracional nem arbitrário, mas em princípio pode ser reconhecido como certo e esta 6 uma situação, facilmente, identificada na enfermagem. A enfermcira reconhece a autoridade do médico e do administrador sobre ela e, ao mesmo tempo, se reconhece como uma autoridade para os auxiliares, atendentes de enfermagem e pacientes, os quais detem menor conhecimento especifico.

Esta postura profissional 6 reforçada pelo ensino que, a todo momento repassa para os estudantes a idéia de que "para ser capaz de mandar fazer, primeiramente, é necessário aprender a fazer". Esta expressão tornouse um jargão na enfermagem, sendo assumido pelo mercado de trabalho que exige do enfermeiro, muito mais a função de gerência do que a assistência direta ao paciente.

Refletindo sobre a evolução da enfermagem, verificamos que a mesma se confirma na colocação de ( $\Lambda \triangle D A M E R(1977)$ de que a tradição é essencialmente conservação e, como tal, nunca deixa de estar presente nas mudanças históricas. Mesmo em tempos revolucionários, em meio às mudanças aparentes das coisas, se conserva muito mais legado antigo do que se acredita, integrando este com o novo sob novas formas.

Por outro lado, também sabemos que quem é responsável em construir a historia somos nós mesmos. Por isso, é imprescindível que os profissionais sejam capazes de identificar e refletir sobre os pró-juizos e tradições que se perpetuam na enfermagem, no sentido de superá-los. Como bem coloca GADAMER(1977), "... a conservaçāo é uma conduta tão livre quanto as inovações e transformações".

\section{CONCLUSÃO}

Na história da enfermagem fica nítida a perpetuação de mitos, estigmas e esterétipos que, ao longo dos anos, vem repercutindo negativamente no desenvolvimento da profissão.

Refletindo sobre essa história, identificamos os pré-juízos e a tradição revivificados na mesma, conforme os concebe GAD AMER(1977).

Ao mesmo tempo, faz-se necessário, não so a identificação desses pré-juizos e dessa tradição, mas também a compreensão e superação dos mesmos pelos profissionais da enfermagem. 
COST $\Lambda$, A.E. et al. The prejudices and tradition in nursing. Rev.Esc.Enf.USP, v.29, n.3, p. 261.66, des. 1995.

The authors try to identify the prejudices and traditions in nursing, thinking about the maintenance of the myths, stigmas and stereotypes troughtout its history, facing the GADAMER's ideas.

UNITERMS: Nursing history. Tradition in nursing. Prejudice in nursing.

\section{REFERÊNCIAS BIBLIOGRÁFICAS:}

1. ALMEIDA, M.C.P. de; ROCHA, J.S.Y. O saber da enfermagem e sua dimensăo prática. Sao Paulo, Cortez. 1986.

2. GADAMER, H. G. Verdad y metodo: fundamentos de una hermenêutica filosófica. Salamanca. Ortega, 1977. P/331.412

3. GERMANO, R.M. Educncão e ideologia da enfermagem no Brasil. Sáo Paulo, Cortez, 1983.

4. HORTA, W.A. Os mitos da enfermagem. Enf. Novas Dimen. v. 1, n.2, p. 60-3, 1975.

5. JAMIESON, E.M. et al . Historia de la enfermeria. $6^{a}$ ed. , México, Interamericana, 1978.

6. PINHEIRO, M.R.S. Razðes para a realização de um inquérito sobre recursos e necessidades de enfermagem. In: SEMINÁRIO INTERNACIONAL SOBRE LEVANTAMENTO DE ENFERMAGEM, Salvador. 1958. Anais, Salvador, (Publicaçoes científicas, n.42), p.5-9.

7. SILVA, G.B. Enfermagem profissional: análise crítica. $2^{a}$ ed., São Paulo, Cortez, 1989. 